\title{
Identifying Barriers to Effective User Interaction with Rehabilitation Tools in the Home
}

\author{
Stephen Uzor, Lynne Baillie, Dawn Skelton, and Fiona Fairlie \\ Multimodal Interaction Research Group, School of Engineering and Computing, \\ Glasgow Caledonian University. 70, Cowcaddens Road, Glasgow, UK \\ \{Stephen.Uzor, L.Baillie, Dawn. Skelton, F.Fairlie\}@gcu.ac.uk
}

\begin{abstract}
This paper presents the results from a user workshop that was undertaken to investigate the relationship between the nature of current home rehabilitation tools and the motivation to exercise. We also present a method of visual feedback which we hope will be an effective tool for informing users regarding important clinical measures associated with their recovery. Older adults over the age of 60 were involved in the study. The findings from the user workshop suggest that the relatively passive nature of current rehabilitation materials is less than ideal for sustaining motivation to exercise. Furthermore, our results suggest that visual feedback and more interactive methods can play an important role in engaging users in home rehabilitation.
\end{abstract}

Keywords: falls prevention; user interaction; rehabilitation; visual feedback; user workshop.

\section{Introduction}

Rehabilitation is often used to improve a person's ability to cope with physical activities in everyday life. In musculoskeletal disorders associated with ageing, rehabilitation usually involves exercises which are designed to increase functional capacity; elevate confidence and encourage independence in older adults [17].

In rehabilitation for falls (and similar conditions affecting strength and balance performance), patients are often given exercises to perform in the home. However, evidence suggests that there is a problem with uptake and adherence to these exercises in the home setting [15]. This could be attributed to a lack of motivation on the user's part [12]. To inform the design of more useful home rehabilitation tools, it is necessary to understand the limitations of the current tools and explore ways in which technology can be used to encourage users to engage in rehabilitation.

This paper describes the proceedings of a user workshop - facilitated by HCI and health researchers - to investigate the effects of user interaction with current home rehabilitation materials on motivation to exercise.

\section{Related Work}

Current evidence suggests that technology can be used to assist rehabilitation in various settings. A preliminary study - using interactive games - conducted by the makers of the 'SilverFit softkinetic rehabilitation system' revealed that the participants often performed more exercise than was required of them as they found most of the games very addictive 
[16]. This system utilized a depth sensing camera that captured the user's image and placed it in a virtual environment where the users could interact with virtual objects. However, this study was limited to the laboratory setting as the equipment required was expensive and bulky.

The study by [18] revealed how video-conferencing over an internet connection enabled users at home to attend a virtual exercise class with other users during pulmonary rehabilitation. The premise behind this study was that, because many patients lived far away from rehabilitation centers, patients (and in some cases, physiotherapists) were required to make frequent long journeys to the classes (or patients' homes). The technology used in the study enabled active involvement in rehabilitation by the participants, who remained motivated.

Previous research has also investigated the use of visual feedback of clinical data to aid rehabilitation in various settings. The findings from these studies propose that, not only can visual feedback of progress be used during rehabilitation to encourage users to exercise; but it can also inform users about important clinical measures associated with their recovery.

MacDonald et al [11] investigated the use of visual feedback of biomechanical data to enhance older adults' understanding of mobility problems that they faced in everyday life. Their visualizations included a 'stick figure' with joints that were illuminated - using green, amber and red colors - depending on the amount of functional demand placed on the users' joints during certain tasks that they performed in everyday life. Their findings suggest that this visual feedback enabled clinicians to communicate effectively with the users about their therapy. In this way, the users felt more involved in their rehabilitation.

\section{Methods}

In order to investigate how the current rehabilitation tools may affect the users' motivation to exercise in the home, we held a user workshop with older adults. The aim of the workshop was to obtain a wide range of opinions on current rehabilitation tools used in the home, which could highlight possible factors affecting motivation and adherence to the programmes. The tools investigated in this study included illustrations and videos containing exercises for the rehabilitation of muscle strength and balance in older adults.

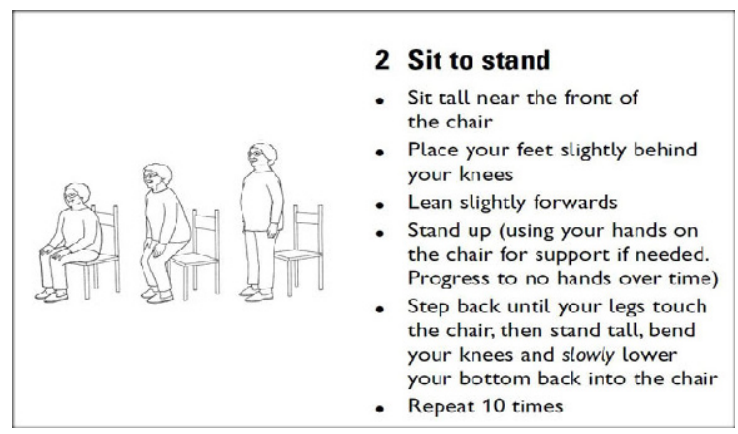

Fig. 1. An illustration of a strength training exercise used in falls rehabilitation in the home 
One exercise - the "sit to stand" (Fig 1) exercise - was chosen as an example. This exercise was available to the participants in both paper and video forms.

Participants were recruited through posters and flyers which were placed at different locations around Glasgow Caledonian University. We recruited 9 healthy older adults ( 8 females and 1 male) between 62 and 75 years of age. The sample size was kept small in order to allow all the participants the opportunity to contribute to each of the phases of the workshop in the two-hour session. All the participants were educated to at least high-school level.

\subsection{User Workshop}

The workshop was divided into a number of phases which employed a range of qualitative techniques identified as effective - based on previous research [2][4] - in obtaining informative comments from participants. There were three groups of participants with a facilitator in each group. Notes were taken during the different phases by experts in the field of user interaction within the research team. The phases are detailed in Table 1.

Table 1. User Workshop Phases

\begin{tabular}{llll}
\hline Phase & Rationale & Procedure & Duration \\
\hline Discussion & $\begin{array}{l}\text { To acquire a range of } \\
\text { opinions regarding the } \\
\text { problems with current } \\
\text { rehabilitation tools }\end{array}$ & $\begin{array}{l}\text { Participants were shown } \\
\text { examples of illustrations and } \\
\text { videos from current } \\
\text { rehabilitation tools. They were } \\
\text { asked to discuss the issues that } \\
\text { users may face while using them } \\
\text { in the home }\end{array}$ & 10 minutes \\
Scenarios & $\begin{array}{l}\text { To provide participants } \\
\text { with everyday usage } \\
\text { scenarios that they can } \\
\text { comment on for their } \\
\text { applicability to a user }\end{array}$ & $\begin{array}{l}\text { User Journey through } \\
\text { rehabilitation using two } \\
\text { personas. Participants were } \\
\text { asked to discuss the issues that } \\
\text { the personas may face in the } \\
\text { relevant scenarios }\end{array}$ & 15 minutes \\
$\begin{array}{l}\text { Demonstratio } \\
\mathrm{n}\end{array}$ & $\begin{array}{l}\text { To obtain feedback on } \\
\text { the usefulness of } \\
\text { visualizations to } \\
\text { highlight progress over } \\
\text { time }\end{array}$ & $\begin{array}{l}\text { Through the use of scenario 3, } \\
\text { the participants were asked to } \\
\text { discuss the use of visual } \\
\text { feedback, showing the results of } \\
\text { a walking test at different stages } \\
\text { of rehabilitation }\end{array}$ & 10 minutes \\
\hline
\end{tabular}

\subsubsection{Discussions on Past Experiences with Rehabilitation}

In this phase of the workshop, we investigated participants' previous experiences with rehabilitation tools similar to the exercise illustrations and videos. It was important to do this, as previous experience with such tools may provide us with some clues regarding the effects of the use of these on their motivation to exercise. 


\subsubsection{Scenarios}

Scenarios are useful in conceptualizing and managing the performance of tasks in certain environments which could improve the usefulness and usability of technology [13]. In this phase of the workshop, the users were provided with 2 personas designed to encapsulate the characteristics of typical users of existing rehabilitation tools. The personas, along with the key characteristics of each one are shown in Table 2 below.

Table 2. Personas

\begin{tabular}{lll} 
Personas & Name & Key Details \\
\hline Persona 1 & Jack Bishop & $\begin{array}{l}\text { 68 year old retired school } \\
\text { coach; suffered stroke at } 65 ; \\
\text { lacks confidence }\end{array}$ \\
Persona 2 & Agnes Newman & $\begin{array}{l}\text { 82 year old retired office } \\
\text { worker; suffered a minor hip } \\
\text { fracture; has fear of falling }\end{array}$ \\
\hline
\end{tabular}

Each of the personas tackled the use of both of these types of media (illustrations and videos) separately. The participants were asked to discuss the issues and challenges facing each individual persona while they performed exercises in the home according to certain set scenarios. Three scenarios were used in the user workshop:

- Scenario 1 - Home rehabilitation session with illustrations of exercises.

- Scenario 2 - Home rehabilitation session with exercise videos.

- Scenario 3 - The use of visual feedback to show improvements in mobility during rehabilitation.

\subsubsection{Feedback on Visualizations}

In this phase of the workshop, the participants were shown a simple animation (created by Glasgow School of Art [10]) of two stick figures walking side by side. One of the stick figures walked with an abnormal gait while the other walked normally. Both figures left a trail of footsteps behind that highlighted the 'Stride Lengths' (an important clinical measure associated with falls risk [6], [9]) of both stick figures. Through Scenario 3, the participants observed how this visual feedback could be shown to Agnes (persona 2) during occasional visits to her home by a physiotherapist. The participants were asked to discuss the usefulness of these visuals in showing the persona's improvements in gait over time.

\section{Findings}

The numerous comments made by the participants in the various phases of the workshop were analyzed and arranged into themes. The following sections highlight some of the main issues shared by the participants across all the groups.

\subsection{Discussion Phase}

None of the participants had previously used such rehabilitation tools. Approximately half of the participants attended exercise classes in a gym. These participants drew 
comparisons between the rehabilitation exercises in the home and the exercise classes in the gym. The main issues shared by the participants in this section were related to the passive nature of the home rehabilitation materials. There were comments that music could engage the users better in the video exercises.

\subsection{Scenario Phase}

One of the main issues raised by the participants in this phase was the duration of exercise when using both the paper and video tools. The participants were aware of the fact that rehabilitation exercises needed to be performed for a minimum of 3 hours a week in order to be effective [19]. However, they suggested that the exercises be split into shorter sessions as the personas may quickly lose interest while using such passive rehabilitation tools.

Table 3 highlights the main issues - facing the personas in the various scenarios identified by the participants.

Table 3. Scenarios (with main issues identified by participants)

\begin{tabular}{|c|c|c|}
\hline Persona & Scenario & Participants Comments \\
\hline Jack & $\begin{array}{l}\text { Rehabilitation session in } \\
\text { the home using exercise } \\
\text { illustrations for } 45 \\
\text { minutes }\end{array}$ & $\begin{array}{l}\text { 1. The exercises should be broken down into } \\
\text { smaller chunks as } 45 \text { minutes is too long to keep } \\
\text { motivated. } \\
\text { 2. The exercise video would be more interactive } \\
\text { than the booklet and would engage him better. } \\
\text { 3. As a retired coach, having to perform exercises } \\
\text { in such a passive manner may reduce his } \\
\text { confidence even further. }\end{array}$ \\
\hline Agnes & $\begin{array}{l}\text { Rehabilitation session } \\
\text { in the home using } \\
\text { exercise videos for } 45 \\
\text { minutes }\end{array}$ & $\begin{array}{l}\text { 1. The pace of the video exercises never changes. } \\
\text { Exercises with more repetitions will be helpful in } \\
\text { later stages of rehab. } \\
\text { 2. Progress cannot be tracked using video } \\
\text { exercises. Agnes lives alone and needs to be } \\
\text { constantly motivated. } \\
\text { 3. Something to interact with would be useful to } \\
\text { Agnes as the video exercises seem passive and } \\
\text { dull. }\end{array}$ \\
\hline
\end{tabular}

The main themes that emerged from the discussions in this phase of the workshop were related to motivation, interactivity and charting progress during rehabilitation. All the participants agreed that the personas required a more interactive solution to home rehabilitation in order to keep them motivated.

\subsection{Visual Feedback of Progress}

Prior to our explaining the concept behind the visual feedback method described in 3.3.3, the participants were asked whether they understood the purpose of the animation. 
A majority of them said that they thought it showed a comparison between one person with abnormal gait and another person walking normally. Initially it was not clear to the participants that both stick figures represented the same individual, but rather highlighted progress during rehabilitation. Interestingly, one of the participants mentioned that the video highlighted stride lengths (drawing the attention of the other participants in their group to the footprints left behind by the stick figures). Others identified specific features of abnormal gait such as: poor balance, apparent muscle damage and knee problems. Subsequent to explaining the purpose of the animation; the participants agreed that Agnes' (persona 2) ability to see improved gait over time during rehabilitation - will improve her confidence and motivate her to exercise. They also mentioned that visuals such as this one would be useful to them if they were in rehabilitation.

\section{Conclusion}

Exercise illustrations and videos currently used in home rehabilitation contain exercises which have been shown in previous research to significantly reduce the risk of falling in older adults. It is necessary for the users to perform these exercises regularly in order to obtain the maximum benefit that they can offer [19]. The findings from the workshop provided us with valuable information as to why users may not use such materials in the home setting. The three key issues that the users of our workshop felt that we should take into consideration when designing tools for home rehabilitation are: progress, interactivity and motivation. If the tools we design do not have these three factors then we may encounter the same problems as befalls the current tools in that they will not be used.

Our findings also suggest that visual feedback can play an important role in home rehabilitation. We discovered that it is not only important that older adults in rehabilitation are constantly motivated to exercise; but that their ability to receive feedback on progress during rehabilitation can improve adherence to home exercise.

\section{Future Work}

One of the limitations of this workshop was that we asked relatively healthy older adults to provide feedback on the use of rehabilitation tools which they had not used previously. We believe that there may be more issues which have not been identified by the scenarios and personas used in this study that we should take into consideration when designing rehabilitation tools for older adults.

In order to identify these issues, we intend to conduct a similar user workshop involving older adults with a history of falls who have previously used exercise illustrations and videos for rehabilitation in the home. By doing this, we anticipate that we will gain a better understanding of the use of these tools; and the factors that contribute to a lack of adherence to exercise programmes. We also intend to recruit a larger sample (16) with an equal balance of male and female participants; as we feel that this would improve the quality of the findings in the next workshop. 
Furthermore, by addressing the issues identified in 4.2, we aim to investigate how rehabilitation tools can be improved in order to enable effective interaction by users.

Acknowledgments. I would like to thank Lee Morton, Mobolaji Ayoade, Glasgow School of Art and the Envisage research team, whose help made the user workshop possible. This research was funded by the MRC Lifelong Health and Wellbeing programme (LLHW).

\section{References}

1. Age UK official website, http://www.ageuk.org.uk/ (last referenced: April 04, 2010)

2. Baillie, L.: The Home Workshop. In: Home-Oriented Informatics and Telematics International Working Conference, California, USA (2003)

3. Benford, S., Bederson, B.D., Akesson, K.P., Bayon, V., Druin, A., Hansson, P., Hourcade, J.P., Ingram, R., Neale, H., O’Malley, C., Simsarian, K.T., Stanton, D., Sundblad, Y., Taxen, G.: Designing Storytelling Technologies to Encourage Collaboration Between Young Children. In: Paper presented at CHI: The Future is Here (2000)

4. Carroll, J.M., Rosson, M.B., Chin, G., Koenemann, J.: Requirements Development in scenario-based design. IEEE Transactions on Software Engineering 24(12), 1156-1170 (1998)

5. Gabbard, J.L., Hix, D., Edward Swan, J.: User-Centered Design and Evaluation of Virtual Environments. IEEE Journal of Computer Graphics and Applications 19(6) (November 1999)

6. Hausdorff, J.: Gait Dynamics, Fractals and Falls. Finding Meaning in the Stride-to-Stride Fluctuations of Human Walking. Hum. Mov. Sci. 26(4), 555-589 (2007)

7. Health Education Authority, Older people and accidents; Fact Sheet 2. HE, London (1999)

8. Kwakkel, G., Van Peppen, R., Wagenaar, R.C., Wood Dauphinee, S., Richards, C., Ashburn, A., Miller, K., Lincoln, N., Partridge, C., Wellwood, I., Langhorne, P.: Effects of augmented exercise therapy time after stroke: a meta-analysis. Stroke 35, 2529-2539 (2004)

9. Lord, S.R., Lloyd, D.G., Sek, K.: Sensori-motor Function, Gait Patterns and Falls in Community-dwelling women. Journal of Age and Ageing 25, 292-299 (1996)

10. Loudon, D., Macdonald, A.S.: Enhancing dialogues between rehabilitation patients and therapists using visualisation software. In: Proc. Envisaging the Future of Home Rehabilitation Workshop. Pervasive Health (2011)

11. MacDonald, A.S., Loudon, D., Rowe, P.J., Samuel, D., Hood, V., Nicol, C., Grealy, M., Conway, B.: Towards a design tool for visualizing the functional demand placed on older adults by everyday living tasks. Universal Access in the Information Society 6, 137-144 (2007)

12. Mataric, M.J., Eriksson, J., Feil-Seifer, D.J., Winstein, C.J.: Socially assistive robots for post-stroke rehabilitation. Journal of NeuroEngineering and Rehabilitation (2007)

13. McKim, R.H.: Experiences in Visual Thinking. PWS Publishers, Boston Mass (1972)

14. Newell, A.F., Arnott, J., Carmichael, A., Morgan, M.: Methodologies for Involving Older Adults in the Design Process. In: Stephanidis, C. (ed.) HCI 2007. LNCS, vol. 4554, pp. 982-989. Springer, Heidelberg (2007), doi:10.1007/978-3-540-73279-2_110 
15. Robinson, L., Dawson, P., Newton, J.: Promoting adherence with exercise-based falls prevention programmes. In: Vincent, M.L., Moreau, T.M. (eds.) Accidental Falls: Causes, Prevention and Intervention, ch. 12, pp. 283-298. Nova Science Publishers, New York (2008)

16. Silver Fit Soft Kinetic rehabilitation (2010), http: / /www. silverfit.nl

17. Skelton, D.A., Dinan, S.M.: Exercise for falls management: Rationale for an exercise programme aimed at reducing postural instability. Journal of Physiotherapy Theory and Practice (1999)

18. Taylor, A., Aitken, A., Godden, D., Colligan, J.: Group pulmonary rehabilitation delivered to the home via the Internet: feasibility and patient perception. In: Proc. CHI 2011 (2011)

19. Taylor, D., Stretton, C.: The Otago Exercise Program, An evidence-based approach to falls prevention for older adults living in the community. Journal of Primary Health Care 31(6) (2004) 